\title{
Morphological and molecular characteristics of Malayfilaria sofiani Uni, Mat Udin \& Takaoka n. g., n. sp. (Nematoda: Filarioidea) from the common treeshrew Tupaia glis Diard \& Duvaucel (Mammalia: Scandentia) in Peninsular Malaysia
}

Shigehiko Uni ${ }^{1,2^{*}}$, Ahmad Syihan Mat Udin', Takeshi Agatsuma ${ }^{3}$, Weerachai Saijuntha ${ }^{3,4}$, Kerstin Junker ${ }^{5}$,

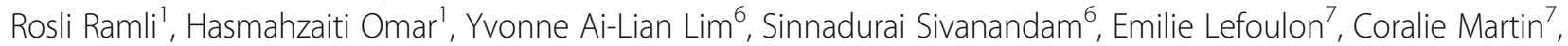
Daicus Martin Belabut', Saharul Kasim', Muhammad Rasul Abdullah Halim', Nur Afiqah Zainuri', Subha Bhassu', Masako Fukuda ${ }^{8}$, Makoto Matsubayashi ${ }^{9}$, Masashi Harada ${ }^{10}$, Van Lun Low ${ }^{11}$, Chee Dhang Chen ${ }^{1}$, Narifumi Suganuma ${ }^{3}$, Rosli Hashim', Hiroyuki Takaoka ${ }^{1}$ and Mohd Sofian Azirun ${ }^{1}$

\begin{abstract}
Background: The filarial nematodes Wuchereria bancrofti (Cobbold, 1877), Brugia malayi (Brug, 1927) and B. timori Partono, Purnomo, Dennis, Atmosoedjono, Oemijati \& Cross, 1977 cause lymphatic diseases in humans in the tropics, while B. pahangi (Buckley \& Edeson, 1956) infects carnivores and causes zoonotic diseases in humans in Malaysia. Wuchereria bancrofti, W. kalimantani Palmieri, Pulnomo, Dennis \& Marwoto, 1980 and six out of ten Brugia spp. have been described from Australia, Southeast Asia, Sri Lanka and India. However, the origin and evolution of the species in the Wuchereria-Brugia clade remain unclear. While investigating the diversity of filarial parasites in Malaysia, we discovered an undescribed species in the common treeshrew Tupaia glis Diard \& Duvaucel (Mammalia: Scandentia).

Methods: We examined 81 common treeshrews from 14 areas in nine states and the Federal Territory of Peninsular Malaysia for filarial parasites. Once any filariae that were found had been isolated, we examined their morphological characteristics and determined the partial sequences of their mitochondrial cytochrome c oxidase subunit 1 (COX1) and 12S rRNA genes. Polymerase chain reaction (PCR) products of the internal transcribed spacer 1 (ITS1) region were then cloned into the pGEM-T vector, and the recombinant plasmids were used as templates for sequencing.

(Continued on next page)
\end{abstract}

\footnotetext{
* Correspondence: unishigehiko@um.edu.my; uni@med.osaka-cu.ac.jp 'Institute of Biological Sciences, Faculty of Science, University of Malaya, Kuala Lumpur 50603, Malaysia

${ }^{2}$ Department of Parasitology, Graduate School of Medicine, Osaka City

University, Osaka 545-8585, Japan

Full list of author information is available at the end of the article
} 
(Continued from previous page)

Results: Malayfilaria sofiani Uni, Mat Udin \& Takaoka, n. g., n. sp. is described based on the morphological characteristics of adults and microfilariae found in common treeshrews from Jeram Pasu, Kelantan, Malaysia. The Kimura 2-parameter distance between the cox1 gene sequences of the new species and $W$. bancrofti was $11.8 \%$. Based on the three gene sequences, the new species forms a monophyletic clade with $W$. bancrofti and Brugia spp. The adult parasites were found in tissues surrounding the lymph nodes of the neck of common treeshrews.

Conclusions: The newly described species appears most closely related to Wuchereria spp. and Brugia spp., but differs from these in several morphological characteristics. Molecular analyses based on the cox 1 and 12S rRNA genes and the ITS1 region indicated that this species differs from both $W$. bancrofti and Brugia spp. at the genus level. We thus propose a new genus, Malayfilaria, along with the new species M. sofiani.

Keywords: Filarial nematodes, Lymphatic filariosis, Molecular identification, Onchocercidae, Scandentia, Southeast Asia

\section{Background}

Filarial nematodes (superfamily Filarioidea Weinland, 1858) parasitise all classes of vertebrates other than fishes and are transmitted by haematophagous arthropods [1-3]. Wuchereria bancrofti (Cobbold, 1877), Brugia malayi (Brug, 1927) and B. timori Partono, Purnomo, Dennis, Atmosoedjono, Oemijati \& Cross, 1977 parasitise humans and are the causative agents of human lymphatic diseases [4-9]. These parasites not only lead to direct health problems but add to the causative agents of tropical diseases which create public health burdens that hinder socioeconomic development in tropical and subtropical regions of the world [10-12].

Recently, there has been a worldwide increase in the incidence of zoonotic infections in humans caused by filarial nematodes that parasitise other animals, such as dogs, cats, cattle and wild boars. It is believed that global warming, deforestation and human demographics are affecting the transmission of parasites by bridging the gaps between vectors, host animals and humans [13]. For example, the number of cases of zoonotic onchocercosis has increased in Europe, the USA and Japan, with infections expanding into areas where the diseases had not previously been reported [14-16]. In Malaysia, $B$. pahangi (Buckley \& Edeson, 1956), a parasite of cats, dogs and wild carnivores, has recently been found to cause zoonotic diseases in humans $[17,18]$.

A total of 34 species of filarioids from 21 genera have previously been recorded from vertebrates in Malaysia [3, 19]. Species in the genera Wuchereria Silva Araujo, 1877 and Brugia Buckley, 1960 have biological similarities with regard to the vectors used and their location in the definitive hosts [4]. Recent molecular analyses have indicated that they are closely related, forming a single clade [20-26]. Based on their geographical distribution, Bain [27] suggested that $W$. bancrofti in humans spread from the Oriental Pacific area through the tropical belt and that Wuchereria and Brugia may have diversified in Southeast Asia. However, the origin and evolution of these species remain to be clarified [23].
To further elucidate the diversity and phylogeny of filarial parasites in Malaysia, we searched for parasites in several wild animal species, including common treeshrews. Common treeshrews (Tupaia glis Diard \& Duvaucel) (Mammalia: Scandentia) are small-bodied mammals that are distributed throughout southern Thailand, Peninsular Malaysia and Borneo. In Peninsular Malaysia, they are still commonly seen in agricultural areas and human habitats. Treeshrews belong to the order Scandentia, which includes the family Tupaiidae [28-30]. Two filarial parasites, i.e. Brugia tupaiae Orihel, 1966 and Mansonella (Tupainema) dunni (Mullin \& Orihel, 1972) have previously been described from common treeshrews in Malaysia [31-34].

During this investigation, we found filarial nematodes in common treeshrews captured in Kelantan, on the east coast of Peninsular Malaysia. None of the specimens collected match any of the hitherto described species or genera of filariae $[2,3,19]$. A new genus and species are, therefore, proposed to accommodate the present nematodes, which are similar to representatives of Wuchereria and Brugia, but distinct from them on the basis of several morphological characters. Analyses of the cytochrome $c$ oxidase subunit 1 ( $\operatorname{cox} 1)$ and $12 \mathrm{~S}$ rRNA genes and the internal transcribed spacer 1 (ITS1) region supported our findings that the new species differs from $W$. bancrofti and Brugia spp. at the genus level, and phylogenetic tree topologies depicted it as sister species of the Wuchereria-Brugia clade.

\section{Methods}

\section{Collection of hosts and parasite material}

Between June 2012 and March 2016, we captured 81 common treeshrews from primary and secondary (second-growth) forests in 14 areas in nine states and the Federal Territory of Peninsular Malaysia: 4 animals from Bukit Kanthan, Perak; 3 from Ulu Kenas, Perak; 18 from Jeram Pasu, Kelantan; 4 from Jeram Linang, Kelantan; 9 from Taman Negara Kelantan; 3 from Genting Highlands, Pahang; 5 from Tioman Island, Pahang; 11 from 
Langkawi Island, Kedah; 7 from Krubong, Melaka; 2 from Perlis State Park; 5 from Gunung Belumut Forest Reserve, Johor; 1 from Kampung Pantai Batu Bukit, Terengganu; 4 from Ulu Gombak, Selangor and 5 from Kuala Lumpur, the Federal Territory. All animals were captured with permission of the Department of Wildlife, Malaysia, using box cage traps baited with palm oil kernels or bananas. The common treeshrews were anaesthetised and sacrificed in accordance with the policy and protocols approved by the Animal Care Committee, University of Malaya, Kuala Lumpur, Malaysia. To obtain adult filariae, we dissected the lymphatic tissues, peritoneal cavity and subcutaneous connective tissues of common treeshrews under a stereomicroscope.

\section{Morphological methods} Newly collected material

Thick blood smears were made and stained with $3 \%$ Giemsa solution ( $\mathrm{pH} 7.4$ ), and skin snips were taken from the face, ears, back, abdomen and tail, as described by Uni et al. [35]. We then searched for microfilariae in the blood smears and skin snips under a compound microscope. We also recorded the length and width of microfilariae taken from the uteri of adult worms.

Isolated adult worms were then transferred into either $70 \%$ ethanol for the examination of fixed worms from one common treeshrew (group A) or into phosphatebuffered saline $(\mathrm{pH}$ 7.4) for the examination of dead unfixed worms from another individual (group B). The fixed adult worms in group A were cleared in lactophenol solution ( $\mathrm{R} \& \mathrm{M}$ Chemicals, Essex, UK) and drawn using a compound microscope equipped with a camera lucida (Olympus U-DA, Olympus, Tokyo, Japan). The midbody region of a fixed female was embedded in paraffin and sections were stained with haematoxylin and eosin. Dead worms that had neither been fixed nor cleared (group B) were also drawn using the same apparatus. For each worm in groups $\mathrm{A}$ and $\mathrm{B}$, we recorded body length, body width, distance between anterior end and nerve ring, distance between anterior end and vulva, length of oesophagus, spicules and tail. Metrical data are presented as the range and measurements are in micrometres unless otherwise indicated.

\section{Additional material examined}

We also examined specimens of $B$. malayi (taken from a human in Pahang, Malaysia, in 1999) and B. pahangi (taken from a domestic cat at Kampung Kerinchi, Kuala Lumpur, in 1999), archived at the Department of Parasitology, Faculty of Medicine, University of Malaya, Malaysia, for comparative purposes. One female (ID no. M1) and one male (ID no. M2) of B. malayi and one female (ID no. M3) and one male (ID no. M4) of $B$. pahangi were fixed in hot $70 \%$ methanol and immersed in glycerine. Microfilariae of each species were examined on thick-blood-film slides stained with Giemsa solution (ID no. MS1 for B. malayi and ID no. MS2 for B. pahangi).

\section{Molecular methods}

Three females (F0, F1 and F2) were transferred directly into $80 \%$ ethanol. DNA extraction, PCR amplification and sequencing were performed as described previously [36-38] to determine the partial sequences of the mitochondrial $\operatorname{cox} 1$ and $12 \mathrm{~S}$ rRNA genes. We also cloned the PCR products of the ITS1 region into pGEM-T vectors and determined the sequences of the recombinant plasmid [39]. Filaria martis Gmelin, 1790 was selected as the outgroup for cox 1 and $12 \mathrm{~S}$ rRNA gene analyses, and Onchocerca spp. were selected for analyses based on ITS1. Sequence data were deposited in the GenBank database (see taxonomic summary). The corresponding GenBank accession numbers of other species used to compare the present specimens and to determine their phylogenetic relationships, are provided in the figures. We used the Kimura 2-parameter model [40] to estimate evolutionary distances between species and calculated K2P distances between species of filarial parasites in MEGA6 as an estimate of the accumulated number of nucleotide substitutions per site [41].

Phylogenetic trees of the nucleotide sequences of the genes were constructed using neighbour-joining (NJ) and maximum-likelihood (ML) methods [41, 42]. Analyses were performed based on $569 \mathrm{bp}$ of the cox1 gene, $319 \mathrm{bp}$ of the 12S rRNA gene and $495 \mathrm{bp}$ of the ITS1 region using MEGA6. Analyses were also performed based on the concatenated alignment $(\operatorname{cox} 1+12 \mathrm{~S}$ rDNA, 888 bp $)$.

\section{Results}

Class Secernentea von Linstow, 1905

Family Onchocercidae Leiper, 1911

Subfamily Onchocercinae Leiper, 1911

\section{Malayfilaria Uni, Mat Udin \& Takaoka n. g.}

\section{Diagnosis}

Anterior extremity slightly expanded into cephalic bulb not set-off from body. Head papillae comprising four labial and four cephalic papillae. Buccal cavity narrow, with pre-oesophageal cuticular ring. Nerve-ring situated at level of muscular oesophagus. Oesophagus divided into short muscular and long glandular parts. Salient cuticular annules present in region of midbody. Female. Vulva at level of anterior part of glandular region of oesophagus. Vagina with two bends. Ovejector long, muscular. Uteri didelphic and opisthodelphic. Tail extremity with two small ventrolateral lappets. Male. 
Area rugosa precloacal. Caudal alae absent. Spicules unequal in length and dissimilar in shape; left spicule long and slender, divided into handle and simple blade, right spicule short and robust. Gubernaculum present. Caudal papillae and two small lappets on tail end present. Tail long, its length almost twice $(1.9 \times)$ width of body at anus. Microfilariae sheathed, with one terminal nucleus; present in peripheral blood. Type-species: Malayfilaria sofiani Uni, Mat Udin \& Takaoka n. sp. Etymology: The generic name is derived from Malaya, the former name of Malaysia.

Malayfilaria sofiani Uni, Mat Udin \& Takaoka n. g., n. sp.

Type-host: Tupaia glis Diard \& Duvaucel (Scandentia: Tupaiidae), common treeshrew.

Type-locality: Jeram Pasu (5.815454, 102.348309), Kelantan, Malaysia.

Type-material: The holotype female (MNHN 95YT) and the allotype male (MNHN 96YT) were deposited in the Muséum National d'Histoire Naturelle, Paris, France. Paratypes (six females: B2, P2 and KE2-5 and nine males: B1, P1, P3-5 and KEM2-5) were deposited in the Institute of Biological Sciences, University of Malaya, Malaysia (accession numbers: Ms-B2, Ms-P2, Ms-KE2-5, Ms-B1, Ms-P1 and Ms-KEM2-5). Collection dates: 16.xi.2013 (group A in treeshrew ID no. 3) and 25.iii.2016 (group B with type specimens in treeshrew ID no. 6).

Site in host: Adult worms invade the tissues surrounding the lymph nodes of the neck of treeshrews. Microfilariae circulate in the blood of treeshrews.

Prevalence and intensity of infection: Two of 81 (2.5\%) treeshrews examined were infected with 12 adult worms each: six female and six male worms in tree shrew ID no. 3 , and seven female and five male worms in treeshrew ID no. 6. Microfilariae were present in five of the examined hosts (6.2\%).

Representative DNA sequences: Sequence data were deposited in the GenBank database as follows: cox 1 (KX944563-KX944565); $12 \mathrm{~S}$ rRNA (KX944560KX944562); and ITS1 (KX944548-KX944559).

ZooBank registration: To comply with the regulations set out in article 8.5 of the amended 2012 version of the International Code of Zoological Nomenclature (ICZN) [43], details of the new species have been submitted to ZooBank. The Life Science Identifier (LSID) of the article is urn:lsid:zoobank.org:pub:36584586-131A-4C30A529-68C47E5920E6. The LSID for the new name Malayfilaria n. g. is urn:lsid:zoobank.org:act:CE9E406CBD20-4BD6-802C-B00FABCF8527 and the LSID for the new name Malayfilaria sofiani Uni, Mat Udin \& Takaoka n. sp. is urn:lsid:zoobank.org:act:22CC40B92427-414D-9D74-0292B7BF53D1.

Etymology: The specific name is chosen in honour of Professor Dr Mohd Sofian Azirun, former Dean of the
Faculty of Science, University of Malaya, for his contributions to entomology and parasitology in Malaysia.

\section{Description}

General. Adult worms small, slender, tapering toward both ends. Anterior extremity slightly dilated, not set-off from remainder of body (Fig. 1a). Labial and cephalic papillae arranged in a circle of four each (Fig. 1b). Amphids lateral, on level of labial papillae. Mouth opening small, followed by pre-oesophageal cuticular ring. Nerve ring surrounding oesophagus on level of muscular part. Deirids not observed. Oesophagus clearly divided into short muscular and long glandular parts. Intestine narrower than glandular oesophagus. Cuticle in midbody region with distinct annules comprising several transverse striations (Fig. 1d); in transverse section, cuticle thickened at lateral chords. Tail moderately long in both sexes.

Female. [Based on the holotype (MNHN 95YT) and nine complete and four fragmented specimens; Figs. 1ag, 2a-c; Additional file 1: Table S1.] Head bulbous, 113128 wide, 111-125 long (Fig. 1a). Buccal cavity with preoesophageal cuticular ring 18-19 wide, 3 high (Fig. 1b). Posterior part of oesophagus very long. Vulva a transverse slit at level of anterior part of glandular oesophagus. Vagina, 219 long, 78 wide, with an initial transverse part, followed by a slight bend and a longer posteriorly directed straight part, followed by a second, sharper bend prior to junction with muscular ovejector (Fig. 1c). Ovejector straight, parallel to oesophagus and posteriorly directed. Tail bent ventrally, extremity rounded, with a pair of rounded ventrolateral lappets (Fig. 1f-g). Phasmids situated at base of lappets (Fig. 1g).

Male. [Based on the allotype (MNHN 96YT) and nine complete and two fragmented specimens; Figs. 1k-r, 2d-e; Additional file 1: Table S1.] Head bulbous, 109 wide, 103-113 long (Figs. 1k, 2d). Buccal cavity with pre-oesophageal cuticular ring 13-15 wide, 4 high (Figs. 1l, 2d). Oesophagus consisting of muscular and long glandular parts (Fig. 1k). Apex of testis at $6.4 \mathrm{~mm}$ from anterior extremity, slightly posterior to oesophagointestinal junction (Fig. 1m). Area rugosa precloacal, consisting of 181-443 raised transverse bands of short longitudinal cuticular crests, 2 high and 4-6 apart, located at 123-863 from tail end (Fig. 1o-p). Left spicule simple, divided into thick-walled handle and approximately twice longer blade with pointed tip. Right spicule divided into thick-walled proximal part and thinnerwalled distal part, with distal bulb encircled by $8-9$ transverse ridges (Fig. 1p). Spicule ratio 3.1-3.8:1. Gubernaculum crescent-shaped, 3 wide in lateral view (Fig. 1p); horseshoe-shaped, 43 long and 3 wide in 


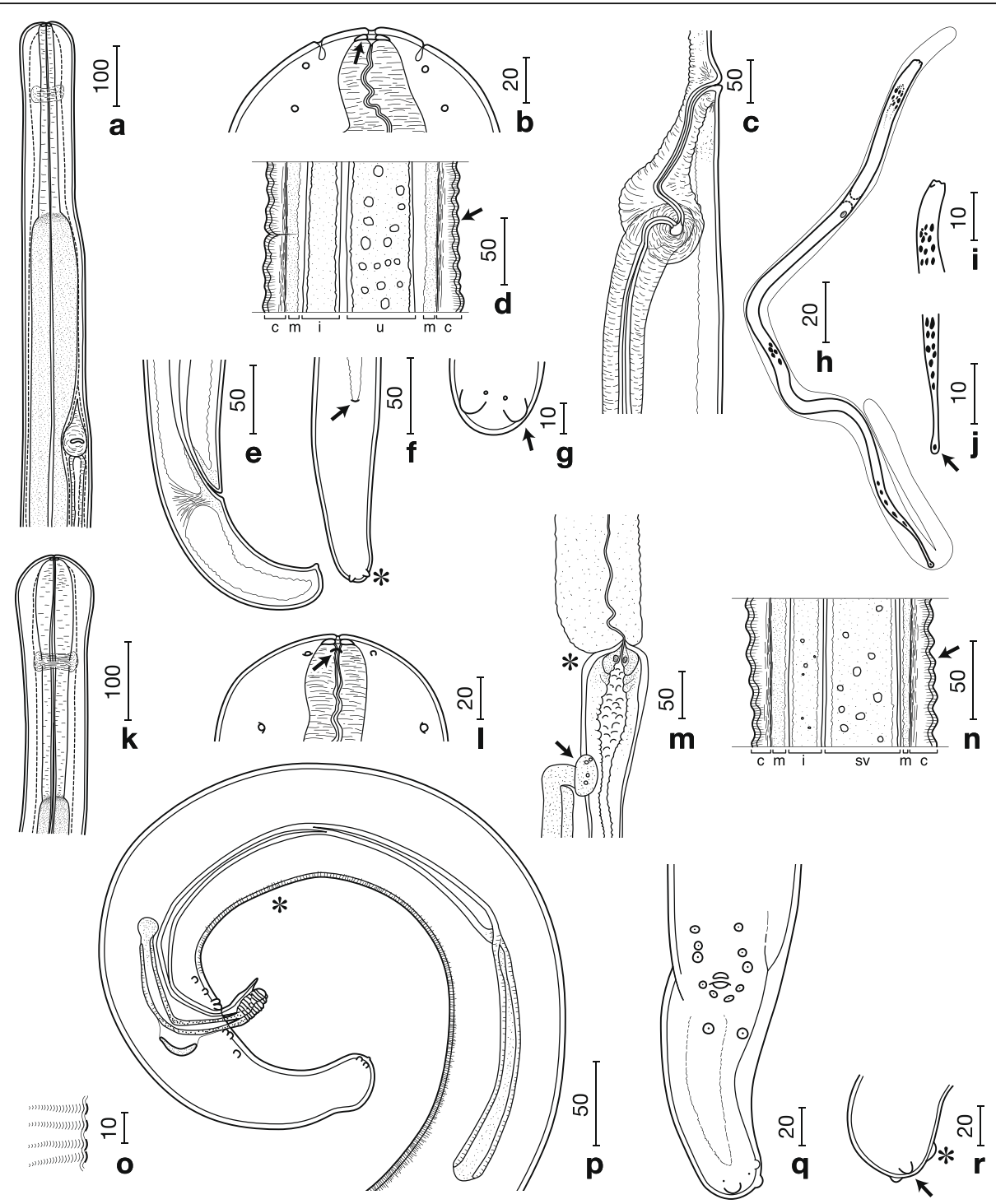

Fig. 1 Camera lucida drawings of Malayfilaria sofiani n. g., n. sp. Females $(\mathbf{a}-\mathbf{g})$, microfilariae $(\mathbf{h}-\mathbf{j})$ and males $(\mathbf{k}-\mathbf{r})$. a Anterior part, right lateral view. b Head, dorsoventral view, showing pre-oesophageal cuticular ring (arrow). c Vagina, right lateral view; d Annules (arrow) at midbody; Abbreviations: c, cuticle; m, muscle; i, intestine; u, uterus. e Posterior part, right lateral view. f Posterior part, ventral view, showing anus (arrow) and lappets $\left({ }^{*}\right)$. $\mathbf{g}$ Lappets (arrow) with phasmidial pore at posterior end, ventral view. h Microfilaria with sheath. $\mathbf{i}$ Head, dorsoventral view. $\mathbf{j}$ Tail tip with terminal nucleus (arrow). k Anterior part, lateral view. I Head with amphid (arrow), lateral view. $\mathbf{m}$ Oesophago-intestinal junction $\left({ }^{*}\right)$ and apex of testis (arrow). $\mathbf{n}$ Annules (arrow) at midbody; Abbreviations: c, cuticle; m, muscle; i, intestine; sv, seminal vesicle. o Area rugosa, lateral view. p Posterior part, right lateral view, showing area rugosa $\left(^{*}\right)$. q Posterior part, ventral view. $\mathbf{r}$ Tail tip with knob $\left(^{*}\right)$ and lappets (arrow), lateral view. Scale-bars are in micrometres

median view. Caudal alae absent. Caudal papillae comprise unpaired ventral median papilla anterior to cloaca and six pairs of subventral papillae arranged as follows: pairs 1-3 precloacal, pair 4 adcloacal, pair 5 postcloacal, slightly more ventrally oriented, pair 6 slightly larger, at level of anterior fourth of tail. Tail bent ventrally, its extremity slightly bulbous, with single large subterminal knob, slightly shifted to left side; single pair of rounded ventrolateral lappets present on tail tip (Fig. 1q-r). Phasmids situated at base of lappets.

Microfilaria. [Figs. 1h-j, 2f-g.] Sheathed unfixed microfilariae $(n=10)$ from uteri of a filarial worm 205-245 long and 5 wide (Additional file 1: Table S1, group B). Sheathed microfilariae $(n=10)$ in thick blood films from a common treeshrew (Additional file 1: Table S1, group 


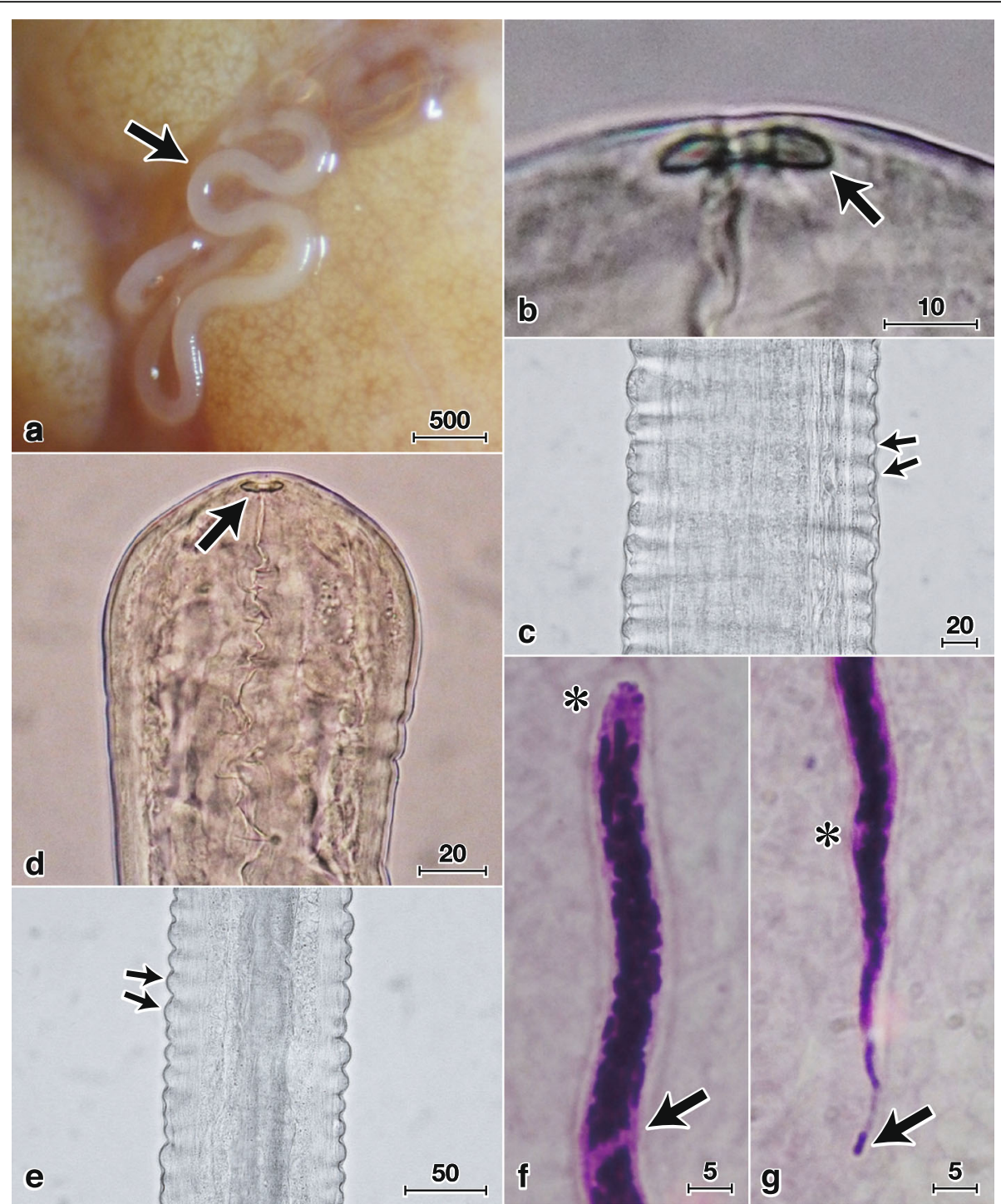

Fig. 2 Micrographs of Malayfilaria sofiani n. g., n. sp. Females (a-c), males (d-e) and microfilariae (f-g). a Adult female (arrow) in tissue surrounding the lymph nodes of the neck of a treeshrew (Tupaia glis). b Pre-oesophageal cuticular ring (arrow). c Annules (arrows) at midbody region. d Bulbous head with pre-oesophageal cuticular ring (arrow). e Annules (arrows) at midbody region. $\mathbf{f}$ Anterior part with cephalic space $\left(^{*}\right)$ and nerve ring (arrow) (Giemsa staining). g Posterior part with anal pore $\left(^{*}\right)$ and terminal nucleus (arrow) (Giemsa staining). Scale-bars are in micrometres

A) 183-240 long and 5-6 wide. Cephalic space 4-8 (2$4 \%$ of body length); distance between anterior end and nerve-ring $37-50$ (22-27\% of body length) (Figs. 1h, 2f); distance between anterior end and excretory pore 59-70 (32-38\% of body length); distance between anterior end and anal pore $143-170$ (77-87\% of body length) (Fig. $2 \mathrm{~g}$ ). Tail 25-43 long (13-23\% of body length) with single nucleus at tail end (Figs. 1j, 2g). Small numbers of microfilariae found in skin snips of a common treeshrew (group A); sheathed, unfixed microfilariae $(n=10)$ from a skin snip 190-233 long and 5 wide.

\section{Prevalence and intensity}

We examined 81 common treeshrews from 14 areas in nine states and the Federal Territory of Peninsular Malaysia for filarial parasites. Microfilariae of $M$. sofiani n. g., n. sp. were present in the blood of five individuals $(6.2 \%)$ collected from a rubber plantation (secondary forest) in Jeram Pasu, Kelantan, Malaysia. From two of the treeshrews harbouring microfilariae, adults were recovered as well (see taxonomic summary). Only a small number of microfilariae were found in skin snips from the two hosts that 
harboured adult worms, whereas large numbers were found in blood smears from these two individuals. Microfilariae from both blood smears and skin snips were very similar in size. Since we also found a small number of blood cells in the skin snips, the microfilariae here appeared to have originated from the blood. We, thus, conclude that microfilariae of the new species circulate in the blood of their hosts. Microfilariae of $B$. tupaiae and $M$. (T.) dunni were not found in the blood smears examined.

\section{Supplementary information on Brugia malayi and B. pahangi}

\section{Brugia malayi}

Female [ID no. M1, Additional file 1: Table S1.] Preoesophageal cuticular ring 10 wide, 3 high. Head bulbous, 25 long, 38 wide, set-off from body, with neck 28 from anterior end. Annules in midbody region absent. Male. [ID no. M2.] Pre-oesophageal cuticular ring 8 wide, 1 high. Head bulbous, 18 long, 28 wide, set-off from body, with neck 20 from anterior end. Annules in midbody region absent; area rugosa just anterior to cloaca. Microfilaria. [ID no. MS1.] Tail tip of sheathed microfilariae with nucleus.

\section{Brugia pahangi}

Female [ID no. M3, Additional file 1: Table S1.] Preoesophageal cuticular ring 8 wide, 1 high. Head bulbous, 20 long, 20 wide, set-off from body, with neck 23 from anterior end. Annules in midbody region absent. Male. [ID no. M4.] Pre-oesophageal cuticular ring 6 wide, 1 high. Head bulbous, 15 long, 18 wide, set-off from body, with neck 18 from anterior end. Annules in midbody region absent. Microfilaria. [ID no. MS2.] Tail tip of sheathed microfilariae with nucleus. This is the first study to give a detailed description of the pre-oesophageal $\mathrm{cu}$ ticular ring in B. pahangi.

\section{Differential diagnosis}

Malayfilaria n. g. is characterised as a member of the subfamily Onchocercinae Leiper, 1911 as defined by Anderson \& Bain [2] on the basis of the following characters: an oesophagus with a well-developed glandular part, and a long tail in both sexes; vulva is located in the anterior region of the body in females, and, in males, spicules differ markedly in size and morphology, sessile caudal papillae are present, whereas caudal alae are absent.

Comparison of morphological characteristics of the present specimens with those of other onchocercine genera revealed close similarities with Wuchereria and Brugia [2, 3, 6, 7], i.e. presence of a buccal cavity with a pre-oesophageal cuticular ring, a dilated cephalic extremity, and a non-protuberant vulva as well as a rounded caudal extremity in females. Furthermore, males have a long tail, with a length almost twice the width of the body at the anus, microfilariae are sheathed and circulate in the blood. However, Malayfilaria n. g. can be distinguished from members of both Wuchereria and Brugia on the basis of a number of morphological characters (Additional file 1: Table S1).

Malayfilaria n. g. differs from Wuchereria as modified by Buckley [7] and characterised by Anderson \& Bain [2] in having fewer caudal papillae (13 vs c. 24) and microfilariae with a terminal nucleus near the tail tip. In addition, the diameter of the cephalic bulb in $M$. sofiani n. g., n. sp. is 1.5 times the size of that recorded in the currently two species included in the genus Wuchereria, W. bancrofti and W. kalimantani Palmieri, Pulnomo, Dennis \& Marwoto, 1980 [44-46], and its glandular oesophagus is six to seven times longer than that in Wuchereria spp. Unlike in Wuchereria spp., salient cuticular annules are present in the midbody region in the new species, but no cuticular bosses were found on the posterior extremity of females. While the morphology of the left spicule is similar in both Wuchereria spp. and M. sofiani n. g., n. sp. in that the blade is simple, spicules differ in length and are shorter in the new species [44, 45].

Both Malayfilaria n. g. and Brugia have microfilariae with terminal nuclei near the tail tip and a similar number of male caudal papillae (13 vs c.11) [2, 7]. However, Brugia, as defined by Buckley [7] and Anderson \& Bain [2] has a left spicule with a complex blade, whereas the blade in the left spicule of Malayfilaria n. g. is simple. In addition, conspicuous annules in the midbody region and lappets at the posterior end, found in both sexes of Malayfilaria n. g., have not been recorded in Brugia spp. [4, 7, 8, 31, 45-54]. The glandular oesophagus in both sexes of M. sofiani n. g., n. sp. was seven to twelve times longer than that of all described Brugia spp. and the spicules of males were also longer than those of Brugia spp. [4, 6, 8, 31, 47-54]. When compared to B. tupaiae, described from the same host species, the diameter of the cephalic bulb of $M$. sofiani n. g., n. sp. was ten times that of $B$. tupaiae and the left spicule was three times longer than that of B. tupaiae (Additional file 1: Table S1).

In a recent comprehensive molecular phylogeny of the Onchocercidae by Lefoulon et al. [26], species of Wuchereria and Brugia formed a strongly supported clade (ONC5) consisting of two further genera of the Onchocercinae, three genera of the Dirofilariinae Sandground, 1921 and four of the Splendidofilariinae Chabaud \& Choquet, 1953. Hence, we compared the morphological characteristics of M. sofiani n. g., n. sp. to the generic diagnoses of the respective genera as well.

Unlike Malayfilaria sofiani n. g., n. sp., species of Mansonella Faust, 1929 (Onchocercinae) do not possess a pre-oesophageal cuticular ring, the oesophagus is undivided and a gubernaculum is absent $[33,34]$. In $M$. 
(T.) dunni, described from the same host as the new species described here, the structure of the right spicule is complex and differs from that in the present specimens [34]. Other than Malayfilaria n. g., microfilariae of species of Breinlia York \& Maplestone, 1926 (Onchocercinae) have no sheath $[2,19,55,56]$.

In contrast with the new genus, males of species of Loa Stiles, 1905, Pelecitus Railliet \& Henry, 1910 and Foleyella Seurat, 1917 (Dirofilariinae) have strongly developed caudal alae with large, pedunculate papillae $[1,2]$. In addition, the oesophagus is undivided in species of both Loa and Foleyella, and species of Pelecitus possess well-developed lateral alae [2]. Furthermore, adults of Loa spp. parasitise primates [2], adults of Pelecitus spp. live among the tendons and muscles near the joints of the legs and feet of birds and mammals (North American lagomorphs and Australian marsupials) [1-3], and adults of Foleyella spp. occur in the subcutaneous connective tissues and body cavity of agamid and chamaeleonid reptiles $[1,3]$.

Contrary to Malayfilaria sofiani n. g., n. sp., species of Cardiofilaria Strom, 1937, Aproctella Cram, 1931, Rumenfilaria Lankester \& Snider, 1982 and Madathamugadia Chabaud, Anderson \& Brygoo, 1959 (Splendidofilariinae) have subequal spicules [2, 3, 57]. Cardiofilaria and Aproctella can be further distinguished from the new genus by caudal papillae that are arranged in a circle or semi-circle around the cloaca of males (sometimes irregularly distributed in Cardiofilaria), and members of both genera are found in the body cavity of birds [1, 2, 58-60]. Adult worms of Rumenfilaria spp. occur in the subserosal connective tissue between folds of the ruminal wall of moose, Alces alces (Linnaeus, 1758), in Canada and further differ from the new genus in having a smooth

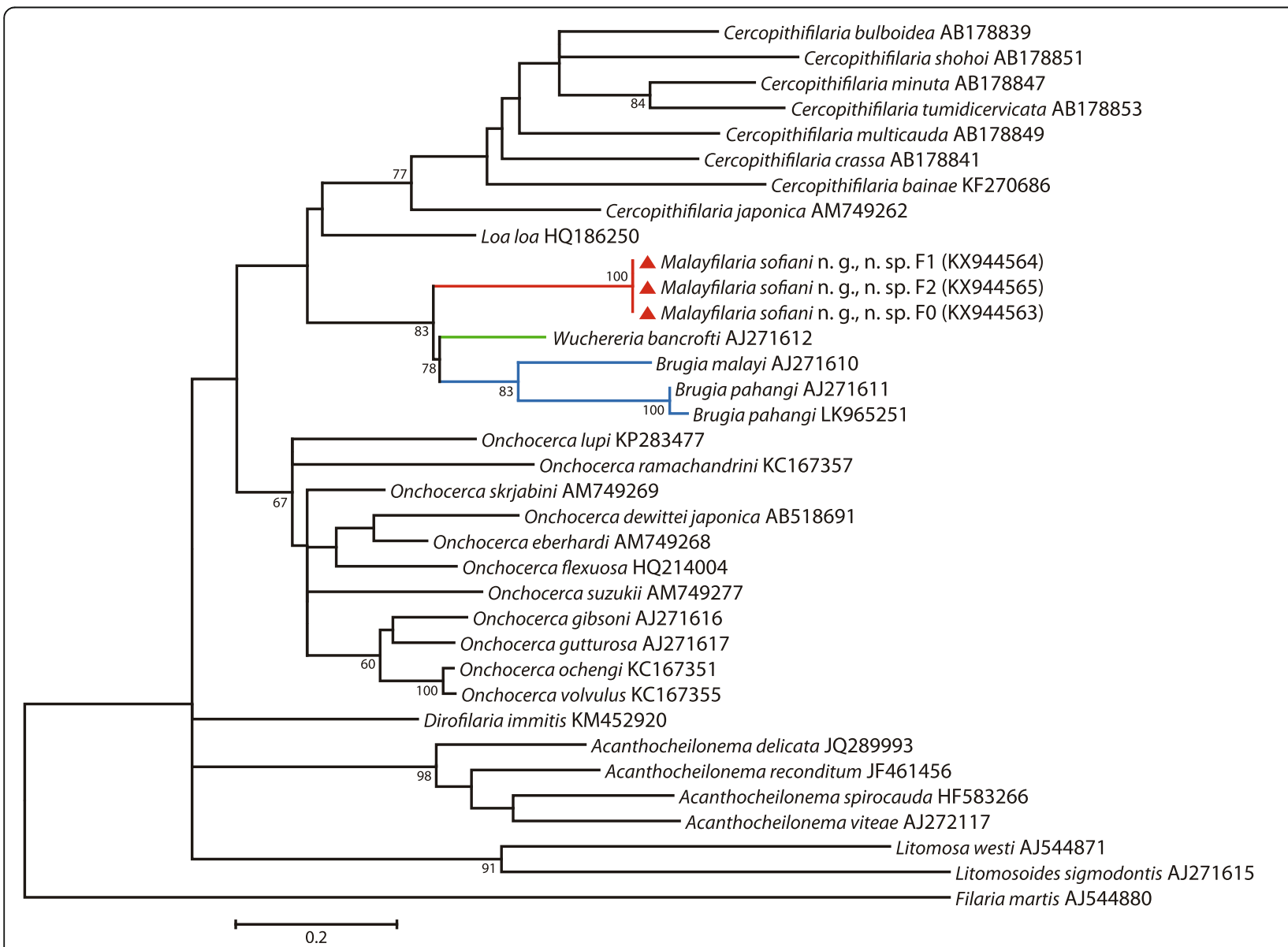

Fig. 3 Taxonomic position of Malayfilaria sofiani n. g., n. sp., inferred using the maximum-likelihood method, based on cox 1 nucleotide sequences. The tree was based on the Tamura-Nei model, which was selected as the best model (MEGA6) with 500 replicates. The percentage of replicate trees in which the associated taxa clustered together is shown next to the branches. Values $>50 \%$ are shown. The tree is drawn to scale, with branch lengths corresponding to the number of substitutions per site. There were a total of 569 positions in the final dataset. The scale-bar below the diagram indicates the number of changes inferred as having occurred along each branch. The red triangles indicate the sequences generated in this study 
cuticle and nine pairs of caudal papillae [3]. Species of Madathamugadia are found in lizards in the Palaearctic and Afrotropics [59-61].

\section{Molecular results}

To elucidate the molecular characteristics of $M$. sofiani n. g., n. sp., we compared the nucleotide sequences of the cox 1 and 12S rRNA genes and the ITS1 region with those of related filarial parasites that were available in the GenBank database. As shown in Additional file 2: Table S2, the K2P distance between sequences of the $\operatorname{cox} 1$ gene of $M$. sofiani n. g., n. sp. and other known species was $11.8 \%$ for $W$. bancrofti, $13.8 \%$ for B. malayi and $14.1 \%$ for B. pahangi. Phylogenetic ML trees based on the cox 1 and $12 \mathrm{~S}$ rRNA genes placed $M$. sofiani n. g., n. sp. as sister species to the clade formed by $W$. bancrofti, B. malayi and B. pahangi, indicating that the new species is closer to W. bancrofti than to Brugia spp. (Figs. 3, 4 and 5). These findings are supported by the tree inferred from the ITS1 region (Fig. 6). The NJ trees for the cox 1 and 12S rRNA genes and the ITS1 region yielded results similar to the ML trees (see Additional file 3: Figure S1; Additional file 4: Figure S2; and Additional file 5: Figure S3).

The K2P distance between the sequences of the cox1 gene of M. sofiani n. g., n. sp. and W. bancrofti was larger than that between $W$. bancrofti and $B$. malayi (10.6\%). The genetic distances between M. sofiani n. g., n. sp. and other related species were $13.7 \%$ for B. (Breinlia) jittapalapongi Veciana, Bain, Morand, Chaisiri, Douangboupha, Miquel \& Ribas, 2015 [55], 13.0-16.9\% for Onchocerca spp., 17.1-21.5\% for Mansonella spp. and $15.8-21.5 \%$ for Cercopithifilaria spp. in the Onchocercinae; $13.2-19.9 \%$ for Loa, Dirofilaria Railliet \& Henry, 1910, Foleyella and Pelecitus in the Dirofilariinae and 13.5-19.4\% for Cardiofilaria, Madathamugadia and Rumenfilaria in the Splendidofilariinae. Based on these morphological and molecular comparisons, as well as

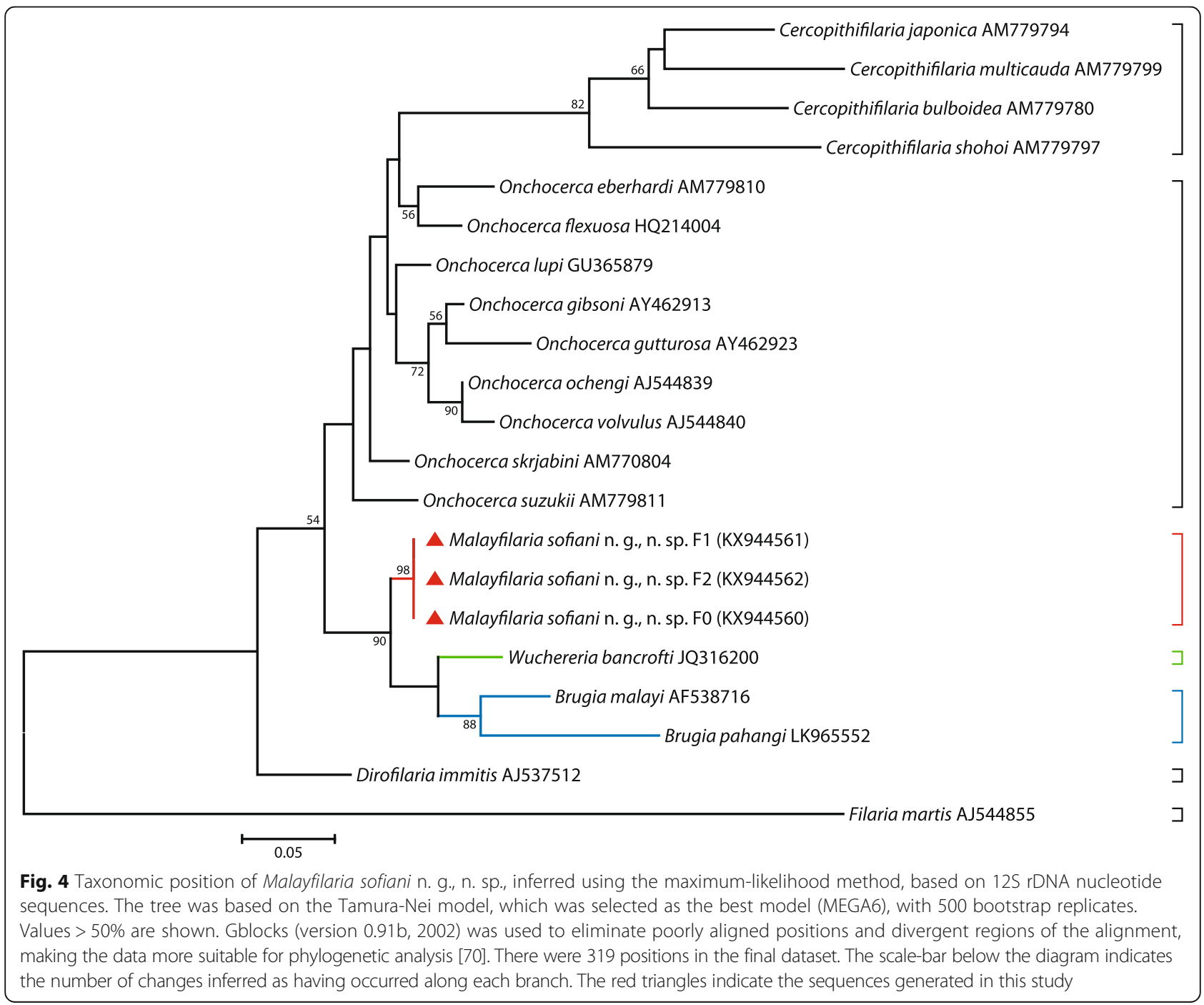




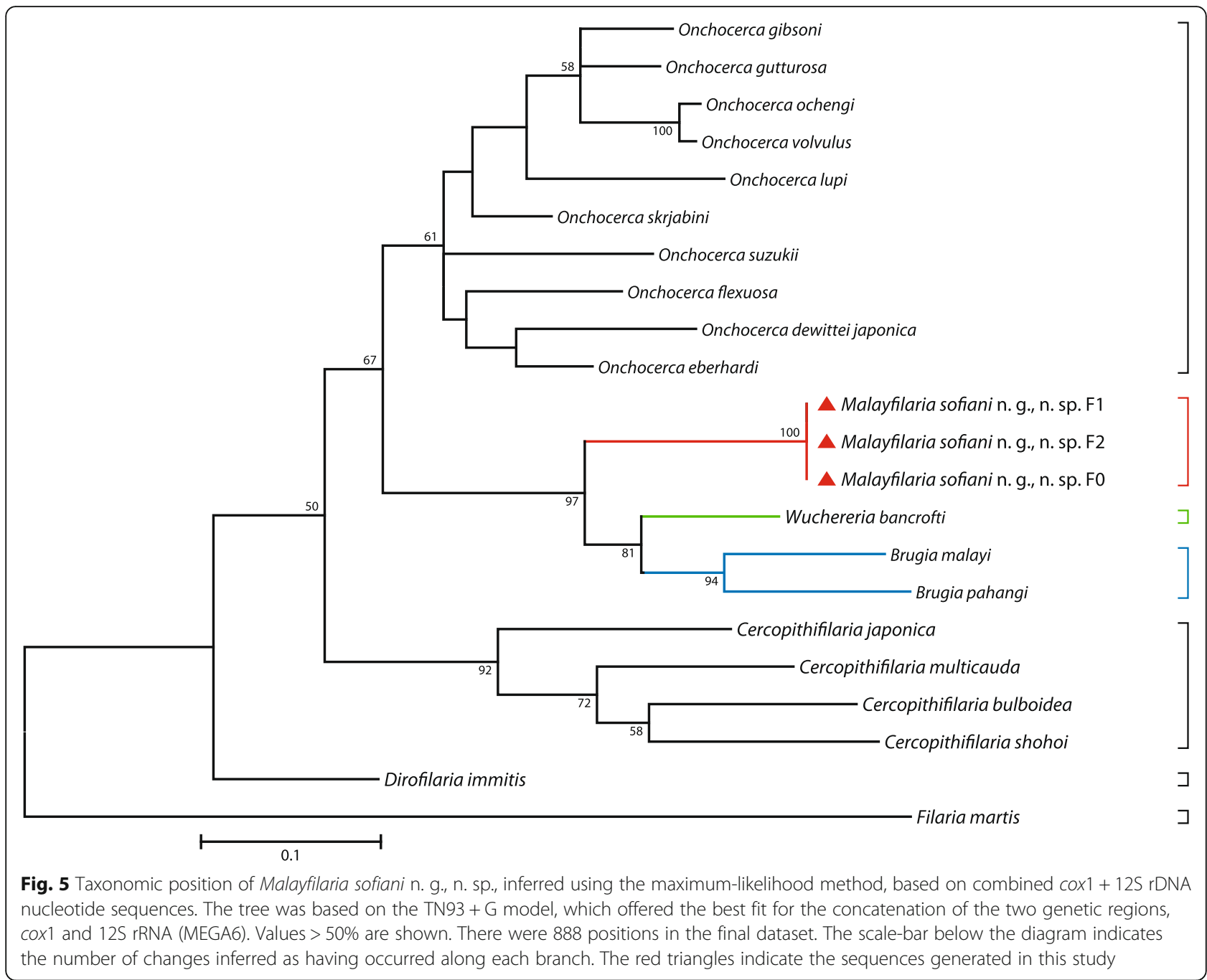

host data and predilection sites, we conclude that the new species is well distinct from previously described genera and we, thus, propose the new genus Malayfilaria in order to accommodate it.

\section{Discussion}

Based on its morphological and molecular characters, $M$. sofiani n. g., n. sp. is most closely related to Wuchereria spp. and Brugia spp. in the Onchocercinae. To date, eight species belonging to these genera have been recorded from various hosts in the Indo-Malayan region. Wuchereria bancrofti, parasitic in humans, occurs throughout the tropics and in some subtropical areas [9], while W. kalimantani was first described in silvered leaf monkeys, Trachypithecus cristatus (Raffles, 1821) (syn. Presbytis cristatus Eschscholtz, 1921), in Kalimantan, Indonesia [44]. Among the ten species belonging to the genus Brugia Buckley, 1958, three, B. malayi, B. pahangi and B. tupaiae, have been discovered in humans, monkeys, carnivores and treeshrews in Malaysia [6, 7, 31]. In Sri Lanka, Brugia buckleyi Dissanaike \& Paramananthan, 1961 has been collected from a Ceylon hare, Lepus nigricollis singhala Wroughton, 1915 [49], and B. ceylonensis Jayewardene, 1962 has been collected from dogs [50]. In addition, $B$. timori has been found in humans in Indonesia [8].

As detailed above, M. sofiani n. g., n. sp. differs from all of these in having an extremely long glandular oesophagus, annulation in the midbody region and small lappets at the terminal end of the tail. In contrast, the pre-oesophageal cuticular ring is a character shared between the three genera. However, despite being mentioned in the description of Wuchereria sp. from a monkey [6] and the inclusion of this character in the generic diagnosis of Brugia by Buckley [7], detailed descriptions of the preoesophageal cuticular ring are so far available for $W$. bancrofti [6, 45, 46], B. malayi [47] and B. patei [48] only. In this study, we provide metrical data for the pre-oesophageal cuticular ring in B. pahangi for the first time. 


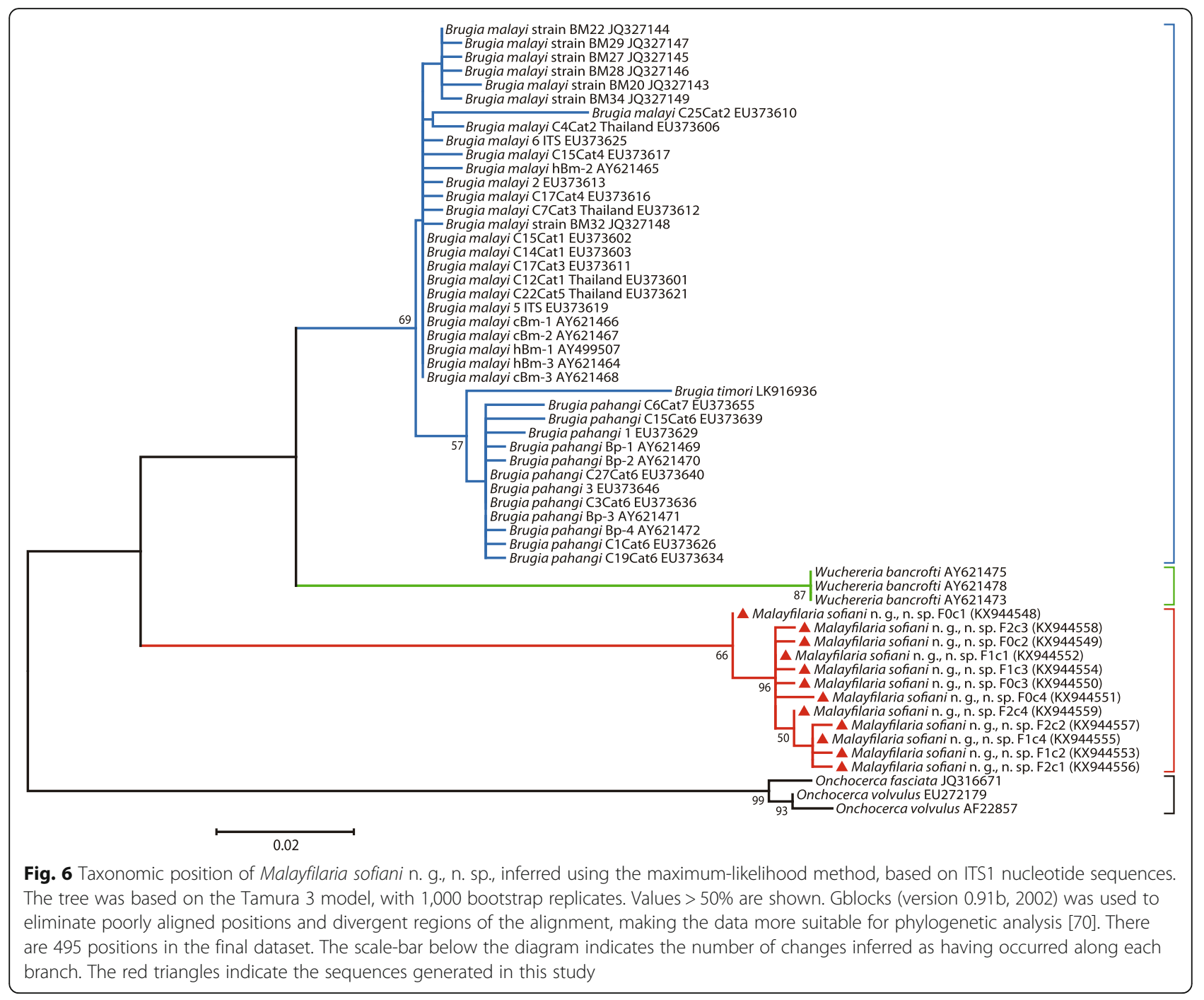

Among the Onchocercidae, Acanthocheilonema spp. also have a salient pre-oesophageal cuticular ring and a stout glandular oesophagus [62, 63], while Cercopithifilaria spp. have a small pre-oesophageal cuticular ring and no glandular oesophagus [62]. Chabaud \& Bain [64] suggested that Cercopithifilaria was derived from the Acanthocheilonema lineage, and a stout glandular oesophagus is considered to be one of the ancestral characteristics in Onchocerca spp. [65]. Based on this, we infer that the new species has ancestral morphological characteristics when compared with Wuchereria spp. and Brugia spp.

In the present study, we carefully extracted specimens of M. sofiani n. g., n. sp. from the tissues of treeshrews under a stereomicroscope and placed them in phosphate-buffered saline (pH 7.4) in Petri dishes. Regardless of whether or not the worms were fixed in alcohol, we usually observed ornamentation in the midbody region of both sexes of the filarioid (Figs. 1d, 1n, 2c, 2e). Based on the definition provided in the $\mathrm{CIH}$ Keys to the Nematode Parasites of Vertebrates
[66], we diagnosed this ornamentation as annules. To the best of our knowledge, the presence of annules is a specific characteristic of the new filarioid described here, although various cuticular ornamentations such as transverse ridges, longitudinal ridges and bosses have been identified previously in filarial parasites [2, 46, 67].

Previous phylogenetic trees based on $12 \mathrm{~S}$ rDNA and cox 1 sequences $[21,22]$, as well as $16 \mathrm{~S}$ rDNA sequences of the endosymbiont bacteria Wolbachia in the host filarioids [21, 24], have shown $W$. bancrofti to be close to Brugia spp. On the basis of multi-locus sequence analyses, Lefoulon et al. [26] separated taxa of the Onchocercidae into five clades; in one of these, ONC5, W. bancrofti, B. pahangi, B. timori and B. malayi formed a monophyletic group. Tree topologies based on the cox 1 and 12S rRNA genes and the ITS1 region obtained in the present study, placed M. sofiani n. g., n. sp. as a sister taxon to the Wuchereria-Brugia clade, represented by $W$. bancrofti on the one hand and B. malayi and $B$. 
pahangi on the other hand. Based on the K2P distance between $\operatorname{cox} 1$ gene sequences, the new species is closest to $W$. bancrofti.

A total of 81 common treeshrews from various areas in Peninsular Malaysia were examined for M. sofiani n. g., n. sp. However, the parasite was present in five host individuals only, all of them captured in Jeram Pasu, Kelantan, a locality on the east coast of Peninsular Malaysia. We conclude that the prevalence of M. sofiani n. g., n. sp. is very low and that it parasitises common treeshrews inhabiting a limited geographical area.

Insects belonging to the family Culicidae are known to act as vectors for $W$. bancrofti and Brugia spp., as well as species of Aproctella and Foleyella [1]. By contrast, M. (M.) ozzardi (Manson, 1897) is transmitted by biting midges (Ceratopogonidae) or black flies (Simuliidae), Loa loa (Cobbold, 1864) by horse flies (Tabanidae), P. fulicaeatrae (Diesing, 1861) by lice (Menoponidae) and M. hiepei HeringHagenbeck, Boomker, Petit, Killick-Kendrick \& Bain, 2000 by sand flies (Psychodidae) [1, 26, 59, 68]. Therefore, although we did not find any potential vectors for $M$. sofiani n. g., n. sp. in the present study, we speculate that the new species is also transmitted by haematophagous arthropods.

Wuchereria bancrofti and W. kalimantani parasitise humans and monkeys, while Brugia spp. parasitise a wide range of hosts, including primates (humans and monkeys), lagomorphs, carnivores and treeshrews [6, 8, 31, 48-53]. Thus, there are no close relationships between the host species of the three filarial genera, Malayfilaria n. g., Wuchereria and Brugia. Phylogenetically, treeshrews belong to the order Scandentia, which is considered to be more closely related to Primates than to Rodentia and Lagomorpha [30]. The common ancestor diverged into Scandentia, Dermoptera and Primates during the Cretaceous (approximately 90 million years ago), and the genus Tupaia Raffles, 1821 arose at the end of the Miocene (approximately 10 million years ago) [69]. Roberts et al. [28] suggested that Miocene tectonic events, volcanism and geographical instability drove treeshrew diversification in Southeast Asia; while according to Bain [27], the radiation of nascent filarial lineages may have occurred with the expansion of mammals between the Paleocene and the Pleistocene (66 to 2.5 million years ago).

With regard to diversification of filariae in the Wuchereria-Brugia clade, Morales-Hojas [23] suggested that co-speciation between the hosts and parasites was the most plausible driving factor, because some species of Brugia and Wuchereria parasitise humans and monkeys. However, he emphasised that more information on the phylogenetic relationships between the species within this clade was required to discuss their evolution. Since $M$. sofiani n. g., n. sp. appears to display more ancestral morphological characteristics than either
Wuchereria spp. or Brugia spp., we speculate that the ancestral lineage of the Wuchereria-Brugia clade may have arisen in Scandentia and transferred to Primates, Carnivora, Rodentia, Lagomorpha and other mammals via its vectors (host switching) and subsequently diversified into Wuchereria spp. and Brugia spp., rather than evolving via host-parasite co-speciation.

\section{Conclusions}

Here, we describe M. sofiani n. g., n. sp., found in the tissues surrounding the lymph nodes of the neck of common treeshrews ( $T$. glis) in Peninsular Malaysia. Adults of the new species differ from Wuchereria spp. and Brugia spp. in having a long glandular oesophagus and annules in the midbody region. Molecular analyses based on the $\operatorname{cox} 1$ gene indicate that $M$. sofiani n. g., n. sp. differs from $W$. bancrofti by $11.8 \%$ and from $B$. malayi by $13.8 \%$. Based on both morphological and molecular characteristics, we conclude that $M$. sofiani n. g., n. sp. is close to $W$. bancrofti in the Wuchereria-Brugia clade.

\section{Additional files}

Additional file 1: Table S1. Comparison of measurements of Malayfilaria sofiani n. g., n. sp. from common treeshrews in Malaysia with other filarial species recorded from treeshrews or hosts in the same geographical region. (XLSX $18 \mathrm{~kb}$ )

Additional file 2: Table S2. The Kimura 2-parameter (K2P) distance between the sequences of the cox 1 gene of Malayfilaria sofiani n. g., $n$. sp. and other known species. (XLSX $14 \mathrm{~kb}$ )

Additional file 3: Figure S1. Taxonomic position of Malayfilaria sofiani n. g., n. sp., inferred using the neighbour-joining method, based on cox1 nucleotide sequences. The tree was based on the Kimura 2-parameter model with 10,000 bootstrap replicates (MEGA6). Numbers at the nodes are the bootstrap confidence values after 10,000 replicates. The percentage of replicate trees in which the associated taxa clustered together is shown next to the branches. Values $>50 \%$ are shown. There were a total of 569 positions in the final dataset. The scale-bar below the diagram indicates the number of changes inferred as having occurred along each branch. Red triangles indicate the sequences generated in this study. (PDF $290 \mathrm{~kb}$ )

Additional file 4: Figure S2. Taxonomic position of Malayfilaria sofiani $\mathrm{n}$. $\mathrm{g}$. n. sp., inferred using the neighbour-joining method, based on $12 \mathrm{~S}$ rDNA nucleotide sequences. The tree was based on the Kimura 2parameter model with 10,000 bootstrap replicates (MEGA6). Gblocks (version 0.91b, 2002) was used to eliminate poorly aligned positions and divergent regions of the alignment [70]. There were 319 positions in the final dataset. The scale-bar indicates the number of changes inferred as having occurred along each branch. Red triangles indicate the sequences generated in this study. (PDF $297 \mathrm{~kb}$ )

Additional file 5: Figure S3. Taxonomic position of Malayfilaria sofiani n. g., n. sp., inferred using the neighbour-joining method, based on ITS1 nucleotide sequences. The tree was based on the Kimura 2-parameter model with 1,000 bootstrap replicates (MEGA6). Gblocks was used to eliminate poorly aligned positions and divergent regions of a DNA alignment [70]. There are 495 positions in the final dataset. The scale-bar indicates the number of changes inferred as having occurred along each branch. Red triangles indicate the sequences generated in this study. (PDF 170 kb)

\section{Abbreviations}

cox 1: cytochrome $c$ oxidase subunit 1 ; ITS1: internal transcribed spacer 1; K2P: Kimura 2-parameter; NJ: neighbour-joining; ML: maximum-likelihood; 
MNHN: Muséum National d'Histoire Naturelle; $\mathrm{ClH}$ : Commonwealth Institute of Helminthology

\section{Acknowledgements}

We are grateful to Academician Dr. Yong Hoi Sen, Senior Fellow of Academy of Sciences Malaysia and Professor Emeritus, University of Malaya, who warmly encouraged us in our research efforts.

\section{Funding}

This work was partly supported by the Ministry of Higher Education, Malaysia (FRGS EP020-2012 to SU; FP060-2014A to SB), BK006-2014 to HO, PG258-2016 to ASMU and the Japan Society for the Promotion of Science, KAKENHI (15 K07781 to MF; 26305011 to TA).

\section{Availability of data and materials}

The data supporting the conclusions of this article are included within the article and its additional files. The holotype and allotype of Malayfilaria sofiani $\mathrm{n}$. g., n. sp. were deposited in the MNHN, Paris, France, under accession numbers MNHN 95YT and MNHN 96YT, and the paratypes were deposited in the Institute of Biological Sciences, University of Malaya, Malaysia under accession numbers Ms-B2, Ms-P2, Ms-KE2-5, Ms-B1, Ms-P1 and Ms-KEM2-5. Sequences were deposited in the GenBank database under accession numbers: coX1 (KX944563-KX944565); 12S rRNA (KX944560-KX944562) and ITS1 (KX944548-KX944559).

\section{Authors' contributions}

SU and ASMU conceived the research and wrote the first draft. SU, K, RR, SS, $\mathrm{MM}, \mathrm{MH}, \mathrm{CDC}, \mathrm{NS}, \mathrm{RH}, \mathrm{HT}$ and MSA performed the morphological studies and contributed to the data analysis and interpretation. TA, WS, HO, YA-LL, $E L, C M, N A Z, S B, V L L$ and MF contributed to the molecular analysis. ASMU, $\mathrm{DMB}, \mathrm{SK}, \mathrm{MRAH}$ and $\mathrm{RH}$ collected samples. All authors read and approved the final manuscript.

\section{Competing interests}

The authors declare that they have no competing interests.

\section{Consent for publication}

Not applicable.

\section{Ethics approval and consent to participate}

All experimental procedures were carried out in strict accordance with the policy and protocols approved by the Animal Care Committee, University of Malaya, Malaysia. The surveys were carried out in accordance with the conservation and control policies of the Department of Wildlife, Malaysia (Permit no. W-00660-16-16).

\section{Publisher's Note}

Springer Nature remains neutral with regard to jurisdictional claims in published maps and institutional affiliations.

\section{Author details}

${ }^{1}$ Institute of Biological Sciences, Faculty of Science, University of Malaya, Kuala Lumpur 50603, Malaysia. ${ }^{2}$ Department of Parasitology, Graduate School of Medicine, Osaka City University, Osaka 545-8585, Japan. ${ }^{3}$ Department of Environmental Medicine, Kochi Medical School, Kochi University, Nankoku 783-8505, Japan. ${ }^{4}$ Walai Rukhavej Botanical Research Institute, Mahasarakham University, Mahasarakham 44150, Thailand. ${ }^{5}$ ARC-Onderstepoort Veterinary Institute, Private Bag X05, Onderstepoort 0110, South Africa. ${ }^{6}$ Department of Parasitology, Faculty of Medicine, University of Malaya, Kuala Lumpur 50603, Malaysia. ${ }^{7}$ UMR7245, MCAM, Muséum National d'Histoire Naturelle, Paris 75005, France. ${ }^{8}$ Research Promotion Institute, Oita University, Oita 879-5593, Japan. ${ }^{9}$ Department of International Prevention of Epidemics, Division of Veterinary Science, Graduate School of Life and Environmental Sciences, Osaka Prefecture University, Osaka 598-8531, Japan. ${ }^{10}$ Laboratory Animal Center, Graduate School of Medicine, Osaka City University, Osaka 545-8585, Japan. ${ }^{11}$ Tropical Infectious Diseases Research \& Education Centre, University of Malaya, Kuala Lumpur 50603, Malaysia.
Received: 3 August 2016 Accepted: 23 March 2017 Published online: 20 April 2017

\section{References}

1. Anderson RC. Nematode parasites of vertebrates: their development and transmission. 2nd ed. Wallingford, UK: CABI; 2000.

2. Anderson RC, Bain O. No. 3. Keys to genera of the order Spirurida, Part 3, Diplotriaenoidea, Aproctoidea and Filarioidea. In: Anderson RC, Chabaud AG, Willmott S, editors. $\mathrm{ClH}$ keys to the nematode parasites of vertebrates. Farnham Royal: Commonwealth Agricultural Bureaux; 1976. p. 59-116.

3. Gibbons LM. Keys to the nematode parasites of vertebrates. Suppl Vol. Wallingford, UK: CABl; 2010.

4. Sonin MD. Filariata of animals and man and diseases caused by them. Part 3, Filariidae, Onchocercinae, Fundamentals of nematology, vol. 24. Moscow: Nauka Publishers; 1975. Translated from Russian, published for the US Department of Agriculture, and the National Science Foundation, Washington, D.C., by New Delhi: Amerind Publishing Co. Pvt. Ltd.; 1985.

5. Rao SS, Maplestone PA. The adult of Microfilaria malayi Brug, 1927. Ind Med Gazette. 1940;75:159-60.

6. Buckley JJC, Edeson JFB. On the adult morphology of Wuchereria sp. (malayi?) from a monkey (Macaca irus) and from cats in Malaya, and on Wuchereria pahangi $\mathrm{n}$. sp. from a dog and a cat. J Helminthol. 1956;30:1-20.

7. Buckley JJC. On Brugia g. nov. for Wuchereria spp. of the 'malayi' group. i.e., W. malayi (Brug, 1927), W. pahangi Buckley and Edeson, 1956, and W. patei Buckley, Nelson and Heisch, 1958. Ann Trop Med Parasitol. 1960;54:75-7.

8. Partono F. Purnomo, Dennis DT, Atmosoedjono S, Oemijati S, Cross JH. Brugia timori sp. n. (Nematoda: Filarioidea) from Flores Island, Indonesia. J Parasitol. 1977;63:540-6.

9. Mak JW. Filariasis: an introduction; an overview of past research. In: Mak JW, editor. Filariasis, vol. 19. Malaysia: Institute for Medical Research; 1983. p. 7-16. Bulletin.

10. WHO. Lymphatic filariasis. Fact sheet No. 102, 2015. http://www.who.int/ mediacentre/factsheets/fs102/en/. Accessed 10 Apr 2016.

11. WHO. Lymphatic filariasis. 2016. http://www.who.int/lymphatic_filariasis/en/. Accessed 10 Apr 2016

12. Melrose WD. Lymphatic filariasis: new insights into an old disease. Int J Parasitol. 2002:32:947-60.

13. Colwell DD, Dantas-Torres F, Otranto D. Vector-borne parasitic zoonoses: Emerging scenarios and new perspectives. Vet Parasitol. 2011;182:14-21.

14. Otranto D, Dantas-Torres F, Cebeci Z, Yeniad B, Buyukbabani N, Boral OB, et al. Human ocular filariasis: further evidence on the zoonotic role of Onchocerca lupi. Parasit Vectors. 2012;5:84

15. Eberhard ML, Ostovar GA, Chundu K, Hobohm D, Feiz-Erfan I, Mathison BA, et al. Case report: zoonotic Onchocerca lupi infection in a 22-month-old child in Arizona: first report in the United States and a review of the literature. Am J Trop Med Hyg. 2013;88:601-5.

16. Uni S, Fukuda M, Otsuka Y, Hiramatsu N, Yokobayashi K, Takahashi H, et al. New zoonotic cases of Onchocerca dewittei japonica (Nematoda: Onchocercidae) in Honshu. Japan Parasit Vectors. 2015:8:59.

17. Tan LH, Fong MY, Mahmud R, Muslim A, Lau YL, Kamarulzaman A. Zoonotic Brugia pahangi filariasis in a suburbia of Kuala Lumpur City. Malaysia Parasitol Int. 2011;60:111-3.

18. Muslim A, Fong MY, Mahmud R, Sivanandam S. Vector and reservoir host of a case of human Brugia pahangi infection in Selangor, peninsular Malaysia. Trop Biomed. 2013;30:727-30.

19. Yen PKF. Taxonomy of Malaysian filarial parasites. In: Mak JW, editor. Filariasis, vol. 19. Malaysia: Institute for Medical Research; 1983. p. 17-35. Bulletin.

20. Xie H, Bain O, Williams SA. Molecular phylogenetic studies on filarial parasites based on 5 S ribosomal spacer sequences. Parasite. 1994;1:141-51.

21. Casiraghi M, Bain O, Guerrero R, Martin C, Pocacqua V, Gardner SL, et al. Mapping the presence of Wolbachia pipientis on the phylogeny of filarial nematodes: Evidence for symbiont loss during evolution. Int J Parasitol. 2004:34:191-203

22. Ferri E, Barbuto M, Bain O, Galimberti A, Uni S, Guerrero RA, et al. Integrated taxonomy: traditional approach and DNA barcoding for the identification of filarioid worms and related parasites (Nematoda). Front Zool. 2009;6:1.

23. Morales-Hojas R. Molecular systematics of filarial parasites, with an emphasis on groups of medical and veterinary importance, and its relevance for epidemiology. Infect Genet Evol. 2009:9:748-59.

24. Ferri $\mathrm{E}$, Bain O, Burbuto M, Martin C, Lo N, Uni S, et al. New insights into the evolution of Wolbachia infections in filarial nematodes inferred from a large range of screened species. PLoS One. 2011;6:e20843. 
25. Eamsobhana P, Lim P-E, Yong HS. Molecular phylogeny of filarial worms (Nematoda: Filarioidea). Raffles Bull Zool. 2013;29:99-109.

26. Lefoulon E, Bain O, Bourret J, Junker K, Guerrero R, Cañizales I, et al. Shaking the tree: Multi-locus sequence typing usurps current onchocercid (filarial nematode) phylogeny. PLoS Negl Trop Dis. 2015;9:e0004233.

27. Bain O. Evolutionary relationships among filarial nematodes. In: Klei TR, Rajan TV, editors. World Class Parasites, The Filaria, vol. 5. Dordrecht: Kluwer Academic Publishers; 2002. p. 21-9.

28. Roberts TE, Lanier HC, Sargis EJ, Olson LE. Molecular phylogeny of treeshrews (Mammalia: Scandentia) and the timescale of diversification in Southeast Asia. Mol Phyl Evol. 2011;60:358-72.

29. Yong HS. Animals, The Encyclopedia of Malaysia, vol. 3. Singapore: Archipelago Press; 1998. p. 38-9.

30. Springer MS, Stanhope MJ, Madsen O, de Jong WW. Molecules consolidate the placental mammal tree. Trend Ecol Evol. 2004;19:430-8.

31. Orihel TC. Brugia tupaiae sp. n. (Nematoda: Filarioidea) in tree shrews (Tupaia glis) from Malaysia. J Parasitol. 1966:52:162-5.

32. Mullin SW, Orihel TC. Tetrapetalonema dunni sp. n. (Nematoda: Filarioidea) from Malaysian tree shrews. J Parasitol. 1972;58:1047-51.

33. Eberhard ML, Orihel TC. The genus Mansonella (syn. Tetrapetalonema): a new classification. Ann Parasitol Hum Comp. 1984;59:483-96.

34. Bain O, Mutafchiev $Y$, Junker $K$, Guerrero R, Martin C, Lefoulon E, et al. Review of the genus Mansonella Faust, 1929 sensu lato (Nematoda: Onchocercidae), with descriptions of a new subgenus and a new subspecies. Zootaxa. 2015;3918:151-93.

35. Uni S, Bain O, Takaoka H, Katsumi A, Fujita H, Suzuki Y. Diversification of Cercopithifilaria species (Nematoda: Filarioidea) in Japanese wild ruminants with description of two new species. Parasite. 2002;9:293-304.

36. Casiraghi M, Anderson TJC, Bandi C, Bazzocchi C, Genchi C. A phylogenetic analysis of filarial nematodes: comparison with the phylogeny of Wolbachia endosymbionts. Parasitol. 2001;122:93-103.

37. Agatsuma T, Iwagami M, Uni S, Takaoka H, Katsumi A, Kimura E, et al. Molecular phylogenetic relationships among seven Japanese species of Cercopithifilaria. Parasitol Int. 2005;54:195-9.

38. Uni S, Fukuda M, Agatsuma T, Bain O, Otsuka Y, Nakatani J, et al. Onchocerca takaokai n. sp. (Nematoda: Filarioidea) in Japanese wild boars (Sus scrofa leucomystax): description and molecular identification of intradermal females. Parasitol Int. 2015;64:493-502.

39. Saijuntha W, Tantrawatpan C, Jarilla BR, Agatsuma T, Andrews RH, Petney TN Intron sequence of the taurocyamine kinase gene as a marker to investigate genetic variation of Paragonimus species in Japan and the origins of triploidy in P. westermani. Trans R Soc Trop Med Hyg. 2016;110:67-73.

40. Kimura M. A simple method for estimating evolutionary rates of base substitutions through comparative studies of nucleotide sequences. J Mol Evol. 1980;16:111-20.

41. Tamura K, Stecher G, Peterson D, Filipski A, Kumar S. MEGA6: molecular evolutionary genetics analysis version 6.0. Mol Biol Evol. 2013;30:2725-9.

42. Saitou N, Nei M. The neighbor-joining method: a new method for reconstructing phylogenetic trees. Mol Biol Evol. 1987;4:406-25.

43. International Commission on Zoological Nomenclature. Amendment of articles 8, 9, 10, 21 and 78 of the International Code of Zoological Nomenclature to expand and refine methods of publication. Zootaxa. 2012:3450:1-7.

44. Palmieri JR, Purnomo, Dennis DT, Marwoto HA. Filarid parasites of South Kalimantan (Borneo) Indonesia. Wuchereria kalimantani sp. n. (Nematoda: Filarioidea) from the silvered leaf monkey, Presbytis cristatus Eschscholts 1921. J Parasitol. 1980:66:645-51.

45. Bain O, Dissanaike AS, Cross JH, Harinasuta C, Sucharit S. Morphologie de Wuchereria bancrofti adulte et sub-adulte. Recherche de caractères différentiels entre les souches. Ann Parasitol Hum Comp. 1985;60:613-30.

46. Bain O, Mutafchiev Y, Junker K. Order Spirurida. In: Schmidt-Rhaesa A, editor. Handbook of Zoology, Vol 2, Nematoda. Berlin: De Gruyter; 2013. p. 661-732.

47. Mutafchiev Y, Bain O, Williams Z, McCall JW, Michalski ML. Intraperitoneal development of the filarial nematode Brugia malayi in the Mongolian jird (Meriones unguiculatus). Parasitol Res. 2014;113:1827-35.

48. Buckley JJC, Nelson GS, Heisch RB. On Wuchereria patei n. sp. from the lymphatics of cats, dogs and genet cats on Pate Island, Kenya. J Helminthol. 1958:32:73-80

49. Dissanaike AS, Paramananthan DC. On Brugia (Brugiella subg. nov.) buckleyi n. sp., from the heart and blood vessels of the Ceylon hare. J Helminthol. 1961;35:209-20.

50. Jayewardene LG. On two filarial parasites from dogs in Ceylon, Brugia ceylonensis n. sp. and Dipetalonema sp. inq. J Helminthol. 1962;36:269-80.
51. Orihel TC. Brugia guyanensis sp. n. (Nematoda; Filarioidea) from the coatimundi (Nasua nasua vittata) in British Guiana. J Parasitol. 1964:50:115-8.

52. Ash LR, Little MD. Brugia beaveri sp. n. (Nematoda: Filarioidea) from the raccoon (Procyon lotor) in Louisiana. J Parasitol. 1964;50:119-23.

53. Eberhard ML. Brugia lepori sp. n. (Filarioidea: Onchocercidae) from rabbits (Sylvilagus aquaticus, S. floridanus) in Louisiana. J Parasitol. 1984;70:576-9.

54. Schacher JF. Morphology of the microfilaria of Brugia pahangi and the larval stages in the mosquito. J Parasitol. 1962;48:679-92.

55. Veciana M, Bain O, Morand S, Chaisiri K, Douangboupha B, Miquel J, et al. Breinlia (Brainlia) jittapalapongi n. sp. (Nematoda: Filarioidea) from the Asian house rat Rattus tanezumi Temminck in Lao PDR. Syst Parasitol. 2015;90: 237-45.

56. Spratt DM. New records of filarioid nematodes (Nematoda: Filarioidea) parasitic in Australasian monotremes, marsupials and murids, with descriptions of nine new species. Zootaxa. 2011:2860:1-61.

57. Bartlett CM, Anderson RC. Filarioid nematodes (Filarioidea: Onchocercidae) of Corvus brachyrhynchos brachyrhynchos Brehm in southern Ontario, Canada and a consideration of the epizootiology of avian filariasis. Syst Parasitol. 1980:2:77-102.

58. Dissanaike AS, Fernando MA. Cardiofilaria nilesi n. sp., recovered from a chicken experimentally infected with infective larvae from Mansonia crassipes. J Helminthol. 1965;39:151-8.

59. Hering-Hagenbeck S, Boomker J, Petit G, Killick-Kendrick M, Bain O. Description of Madathamugadia hiepei n. sp. (Nematoda: Splendidofilariinae), a parasite of a South African gecko, and its development in laboratory bred Phlebotomus dubosai (Diptera: Psychodidae). Syst Parasitol. 2000:47:207-13.

60. Bain O, Petit G, Kozek WJ, Chabaud A-G. Sur les filaires Splendidofilariinae du genre Aproctella (1). Ann Parasitol Hum Comp. 1981;56:95-105.

61. Bain O, Wanji S, Petit G, Paperna I, Finkelman S. Filaires Splendidofilariinae de lézards: nouvelles espèces, redescription, cycle chez phlébotome. Syst Parasitol. 1993;26:97-115.

62. Bain O, Baker M, Chabaud AG. Nouvelles données sur la lignée Dipetalonema (Filarioidea, Nematoda). Ann Parasitol Hum Comp. 1982;57:593-620.

63. Uni S, Bain O, Suzuki K, Agatsuma T, Harada M, Motokawa M, et al. Acanthocheilonema delicata n. sp. (Nematoda: Filarioidea) from Japanese badgers (Meles anakuma): Description, molecular identification, and Wolbachia screening. Parasitol Int. 2013;62:14-23.

64. Chabaud AG, Bain O. The evolutionary expansion of the Spirurida. Int J Parasitol. 1994;24:1179-201.

65. Yagi K, Bain O, Shoho C. Onchocerca suzukii n. sp. and O. skrjabini (= O. tarsicola) from a relict bovid, Capricornis crispus, in Japan. Parasite. 1994;1:349-56.

66. Willmott S. No 1. Glossary of Terms. In: Anderson RC, Chabaud AG, Willmott S, editors. $\mathrm{ClH}$ Keys to the Nematode Parasites of Vertebrates. Farnham Royal: Commonwealth Agricultural Bureaux; 1974. p. 1-5.

67. Mutafchiev Y, Dantas-Torres F, Giannelli A, Abramo F, Papadopoulos E, Cardoso $L$, et al. Redescription of Onchocerca lupi (Spirurida: Onchocercidae) with histopathological observations. Parasit Vectors. 2013;6:309.

68. Bain O, Petit G, Paperna I, Finkelman S, Killick-Kendrick M. A new filaria of a lizard transmitted by sandflies. Mem Inst Oswaldo Cruz. 1992;87 Suppl 1:21-9.

69. Janečka JE, Miller W, Pringle TH, Wiens F, Zitzmann A, Helgen KM, et al. Molecular and genomic data identify the closest living relative of Primates. Science. 2007:318:792-4.

70. Castresana J. Selection of conserved blocks from multiple alignments for their use in phylogenetic analysis. Mol Biol Evol. 2000;17:540-52.

\section{Submit your next manuscript to BioMed Central and we will help you at every step:}

- We accept pre-submission inquiries

- Our selector tool helps you to find the most relevant journal

- We provide round the clock customer support

- Convenient online submission

- Thorough peer review

- Inclusion in PubMed and all major indexing services

- Maximum visibility for your research

Submit your manuscript at www.biomedcentral.com/submit 